\title{
AVALIAÇÃO DO CONTEXTO DE TRABALHO E CUSTO HUMANO DO TRABALHO ENTRE TÉCNICOS ADMINISTRATIVOS DE UMA INSTITUIÇÃO PÚBLICA DE ENSINO SUPERIOR NA PARAÍBA
}

\author{
EVALUATION OF THE WORK CONTEXT AND HUMAN COST OF \\ WORK AMONG ADMINISTRATIVE TECHNICIANS OF A PUBLIC \\ INSTITUTION OF HIGHER EDUCATION IN PARAÍBA
}

Letícia de Macêdo Nóbrega Aires ${ }^{1}$ Maria do Socorro Rocha Melo Peixoto ${ }^{2}$ Clésia Oliveira Pachú ${ }^{3}$

RESUMO: OBJETIVO: Investigar a situação de trabalho e os riscos de adoecimento de um grupo de técnicos administrativos da Universidade Estadual da Paraíba. MÉTODO: A pesquisa apresenta caráter exploratório e descritivo com a participação de 91 servidores técnicos administrativos efetivos, de ambos os sexos, com atividade laboral executada na Universidade Estadual da Paraíba. A amostra foi formada pelo maior número possível de participantes que foram incluídos conforme a acessibilidade e disponibilidade em colaborar com a pesquisa. Os instrumentos utilizados para realização da pesquisa foi a Ficha Sócio Demográfica e duas escalas do Inventário sobre Trabalho e Riscos de Adoecimento - ITRA que são: Escala de Avaliação do Contexto de Trabalho (EACT), Escala de Custo Humano do Trabalho (ECHT). RESULTADOS: No trabalho dos técnicos administrativos existem vivências de prazer, mas, também de sofrimento, onde, o prazer está relacionado às relações sócias profissionais e os fatores sociais e psicológicos. CONCLUSÃO: Percebe-se a importância de um olhar voltado para a saúde do trabalhador, onde, os riscos de adoecimento são visíveis, o que gera uma responsabilidade para o melhor cuidado da saúde dos técnicos administrativos da referida universidade.

Palavras chave: Categoria de Trabalhadores. Riscos Ocupacionais. Trabalho.

\footnotetext{
${ }^{1}$ Graduanda de Fisioterapia pela Universidade Estadual da Paraíba - UEPB, Campus I, Campina Grande, PB.

${ }^{2}$ Doutora, Docente da Universidade Estadual da Paraíba- UEPB, Campus I, Campina Grande, PB.

${ }^{3}$ Doutora, Docente da Universidade Estadual da Paraíba - UEPB, Campus I, Campina Grande, PB.
} 
ABSTRACT: OBJECTIVE: to investigate the work situation and the risks of illness of a group of administrative technicians from the State University of Paraiba. METHOD: exploratory and descriptive character with the participation of 91 effective administrative technical servants, of both sexes, with work activity performed at the State University of Paraiba. The sample was formed by the largest possible number of participants who were included according to accessibility and availability to collaborate with the research. The instruments used to carry out the research were the Socio-Demographic Form and two scales of the Inventory on Work and Risks of IIIness - ITRA which are: Work Context Assessment Scale (EACT), Human Labor Cost Scale (ECHT). RESULTS: in the work of administrative technicians there are experiences of pleasure, but also of suffering, where pleasure is related to professional partner relationships and social and psychological factors. CONCLUSION: we perceive the importance of a look at the health of workers, where the risks of illness are visible, which generates a responsibility for the better health care of the administrative technicians of the university.

Keywords: Category of Workers. Occupational Risks. Work. 


\section{INTRODUÇÃO}

Trabalhador representa toda pessoa que exerça atividade de trabalho, independentemente de estar inserido no mercado formal ou informal, inclusive trabalho familiar e/ou doméstico. O termo Saúde do Trabalhador compreende as relações entre trabalho e o processo saúde/doença. Assim, a saúde e a doença são consideradas processos dinâmicos, estreitamente articulados com os modos de desenvolvimento produtivo da humanidade. Então, a forma de inserção dos homens, mulheres e crianças no espaço de trabalho contribui decisivamente para formas específicas de adoecer e morrer (BRASIL, 2018).

Neste sentido, para inserção dos trabalhadores no mercado de trabalho devem ser considerados os diversos riscos ambientais e organizacionais aos quais estão expostos, entendendo que irão variar de acordo com o tipo de bem ou serviço produzido. O Ministério do Trabalho classifica os riscos ocupacionais em 05 grupos: químicos, físicos, biológicos, de acidentes e ergonômicos. Já, o Ministério da Saúde reconhece os seguintes grupos de riscos: físicos, químicos, biológicos, mecânicos, de acidentes, ergonômicos e psicossociais (BRASIL, 2018; RIBEIRO, 2012).

As doenças ocupacionais estão relacionadas ao conjunto de enfermidades adquiridas ou agravadas pela exposição a fatores de risco associados ao trabalho (OLIVEIRA, 2013). Assim, são indicadores das condições laborais e se constituem problema de saúde pública. Tais doenças são responsáveis por sofrimento para o indivíduo e sua família, sendo também prejudiciais ao empregador e sistema público de saúde (OIT, 2013).

O serviço público enfrentou tempo de transformações, devido ao processo de globalização. Aspectos como o individualismo, competitividade entre os colegas como resultado da avaliação de desempenho individual -, ausência de confiança e cooperação, imposição pelo uso da tecnologia, não participação laboral, compõem contexto de relações socioprofissionais. Tais ações desestruturam emocionalmente 
os trabalhadores, podendo levá- los até a desistência do emprego (RIBEIRO; SANTOS; MANCEBO, 2013).

No serviço público ocorrerão situações que podem influenciar a saúde e bemestar do trabalhador, daí a necessidade de considerar ações de prevenção e promoção de saúde dos mesmos. Dentre estas situações citam-se vários riscos de acordo com diversos cargos e funções; tensões existentes entre exigências burocráticas e políticas; a instabilidade relacionada às mudanças políticas, a exigência pela produtividade e eficiência tendo como referência o setor privado; o conflito entre os poderes burocrático, técnico e político e, ainda, a imagem depreciativa do servidor público perante a sociedade, fato bastante corriqueiro na atualidade (TRAESEL e MERLO, 2014).

O servidor técnico-administrativo que trabalha na educação desenvolve atividades estratégicas de suporte ao processo de formação técnica e profissional dos alunos, no âmbito da política da educação pública, de qualidade e gratuita, prestando, portanto, importantes serviços à sociedade (CAMPOS, 2016). A Qualidade de Vida no Trabalho de funcionários técnico-administrativos de Instituições Públicas de Ensino Superior brasileiras apresenta como fatores mais críticos os referentes as oportunidades de desenvolvimento profissional, planos de carreira e remuneração e, condições de trabalho. Estas relacionadas a aspectos de saúde e segurança ou à adequação de equipamentos (COSTA, 2017). Assim, de acordo com o exposto, objetivou-se avaliar o contexto de trabalho e custo humano do trabalho entre técnicos-administrativos de uma instituição pública de ensino superior na Paraíba.

\section{METODOLOGIA}

A metodologia da pesquisa foi de caráter exploratório e descritivo, pois procurou tornar o fenômeno mais explícito e analisar sua ocorrência, estabelecendo relações entre as principais variáveis do estudo (contexto de trabalho, custo humano, danos físicos e psicossociais) sem manipulá-las. 
A amostra foi composta a partir de uma estratégia acidental, definida como não- probabilística, sendo formada pelo maior número possível de participantes que vão sendo incluídos conforme a acessibilidade e disponibilidade em colaborar com a pesquisa. Tal acessibilidade foi mediada pelos chefes de cada setor, sendo os instrumentos preenchidos por todos os técnicos administrativos que aceitaram voluntariamente participar do estudo. Assim, participaram da pesquisa 91 servidores técnicos administrativos.

A pesquisa foi realizada no Campus I, da Universidade Estadual da Paraíba o qual está localizado na Rua Baraúnas, n. 351, Bairro Universitário, em Campina Grande-PB com os servidores técnicos administrativos. Como critério de inclusão foram considerados servidores técnicos-administrativos efetivos, de ambos os sexos, com atividade laboral executada na UEPB. Nos critérios de exclusão estão servidores técnicos não efetivos, servidores afastados de suas funções ou cedidos para outras instituições e trabalhadores que não desempenham sua função na instituição.

Entre os instrumentos utilizados para realização da pesquisa foi a Ficha Sócio Demográfica para coletar informações relativas as questões Socioeconômico, visando coletar informações relativas ao perfil biográfico e sócio ocupacional (idade, sexo, estado civil, nível de instrução escolar, número de filhos tempo de serviço, renda e afastamento do trabalho por problemas de saúde relacionados ao trabalho) a fim de caracterização da amostra.

Outro instrumento utilizado foi o Inventário sobre Trabalho e Riscos de Adoecimento - ITRA. Esse instrumento foi construído e validado por Ferreira e Mendes (2003) em pesquisa nacional com auditores fiscais da Previdência Social Brasileira, sendo posteriormente adaptado e validado com outras amostras ocupacionais (MENDES; FERREIRA, 2007). Os autores recomendam seu uso para fins de diagnóstico ocupacional e para pesquisas acadêmicas voltadas a melhoria da saúde e qualidade de vida do trabalhador. O ITRA, em seu formato completo, é composto por quatro escalas que mensuram distintas e interdependentes modalidades de representações dos respondentes relativas ao mundo do trabalho, sendo quena presente pesquisa foram utilizadas duas escalas. 
A primeira, denominada de Escala de Avaliação do Contexto de Trabalho (EACT) que reúne 31 itens que variam de 1 a 5 pontos, distribuídos em três fatores: F1) Organização do Trabalho, que diz respeito à divisão e conteúdo das tarefas, normas, controle e ritmos de trabalho; F2) Condições de Trabalho, referente a qualidade do ambiente físico, posto de trabalho, equipamentos e material disponibilizado para a execução da tarefa e; F3) Relações Sócio profissionais, referente aos modos de gestão do trabalho, comunicação e interação profissional.

A segunda, denominada de Escala de Custo Humano do Trabalho (ECHT) é formada por 32 itens que variam de 1 a 5 pontos, distribuídos em três fatores: F1) Custo Físico, relativo ao dispêndio fisiológico imposto ao trabalhador pelas características do contexto produtivo; F2) Custo Cognitivo, que indica o dispêndio intelectual para a aprendizagem, resolução de problemas e tomada de decisão no trabalho e; F3) Custo Afetivo, que aborda o dispêndio emocional sob a forma de reações afetivas, sentimentos e de estado de humor.

A coleta de dados teve início após a aprovação do Comitê de Ética da Universidade Estadual da Paraíba (UEPB) com parecer de aprovação: ${ }^{\circ} 3.124 .214$ como rege a resolução 466/2012 do Conselho Nacional de Saúde/MS. Assim, participaram da pesquisa os técnicos de ambos os sexos que estavam em pleno exercício da função e que aceitaram assinar o Termo de Consentimento Livre e Esclarecido (TCLE) em duas vias, ficando uma em posse doparticipante, e a outra, do (a) pesquisador (a).

Foi realizada a aplicação do questionário contendo o perfil socioeconômico, as três escalas do ITRA e o QNSO, no tempo conveniente ao técnico administrativo. Cada participante respondeu aos questionários no próprio local de trabalho. Antes de receber os questionários, todos foram informados sobre os objetivos e os aspectos éticos da pesquisa. Feito isto, era realizado o preenchimento do questionário e o pesquisador permanecia no local para esclarecer eventuais dúvidas. $O$ tempo gasto para responder todas as questões era de aproximadamente 15 minutos.

As respostas contidas nos questionários foram digitadas na forma de banco de dados no Excel e, em seguida, examinado a consistência interna dos fatores, calculada por meio do Alfa de Cronbach, onde o resultado da análise da EADRT foi 
de 0,94 sendo classificada como muito boa, atendendo aos critérios dos estudos, sendo possível utilizar análises estatísticas. Para Mendes e Ferreira (2007) considera-se como resultado para a Escala de Avaliação dos Danos Relacionados ao Trabalho (EADRT) os seguintes valores: Acima de $3,7=$ avaliação mais negativa, grave; Entre 2,3 e 3,69 = avaliação mais moderada, crítico; Abaixo de 2,29 = avaliação mais positiva, satisfatório. Também foram efetuadas as análises descritivas (média, desvio-padrão e porcentagem) para delinear o perfil socioeconômico da amostra e observar osindicadores descritivos da distribuição dos escores individuais obtidos em cada fator.

\section{RESULTADOS E DISCUSSÕES}

\section{Resultados do Questionário socioeconômico}

Dos 91 técnicos administrativos que responderam ao questionário sócio demográfico 49 são do sexo masculino e 42 feminino, totalizando uma população $54 \%$ masculina e $46 \%$ feminina. Quanto a faixa etária a população foi classificada em: de 21 a 30 anos, $n=38$ (42\%), de 31 a 40 anos, $n=45$ (49,4\%), de 41 a 50 anos, $n=4(4,3 \%)$, de 51 a 60 anos, $n=3(3,3 \%)$ e de 61 a 70 anos, $n=1(1 \%)$.

Em relação à formação acadêmica a população é composta por: 14 pessoas com ensino superior incompleto (15\%), 30 com ensino superior completo (33\%) e 47 pós-graduados (52\%). Evidenciando uma grande maioria graduado e pós-graduado, representando $85 \%$ da população.

Quanto ao estado civil 33 pessoas classificaram-se como casadas, totalizando $36,3 \%$ da população, 56 solteiras, totalizando $61,53 \%$ da população e 2 pessoas divorciadas, correspondendo a $2,2 \%$ da população. Já com relação ao número de filhos, 61 pessoas não têm filhos (67\%), 17 tem apenas um filho $(18,7 \%)$, 9 pessoas têm dois filhos (10\%), 3 pessoas têm três filhos (3,3\%) e 1 pessoa tem quatro filhos $(1 \%)$. 
Quanto a renda, 16 pessoas não declaram (17,6\%), 6 pessoas recebem de 1 a 2 salários mínimos (7\%), 45 pessoas recebem de 3 a 4 salários mínimos (49,4\%), 23 pessoas recebem de 5-6 salários mínimos (25,3\%), 1 pessoa recebe acima de 6 salários mínimos (1\%).

Quanto ao tempo de serviço, 33 trabalham de 1 a 11 meses na instituição (36,3\%), 18 trabalham de 1 a 5 anos na instituição (19,8\%), 27 trabalham de 6 a 10 anos na instituição (29,6\%), 9 trabalham de 11 a 15 anos na instituição (10\%), nenhum trabalha de 16 a 20 anos (0\%), 3 trabalham de 21 a 35 anos (3,3\%) e uma pessoa trabalha a mais de 36 anos na instituição (1\%).

Uma das perguntas era sobre afastamento do trabalho por problemas de saúde relacionados ao trabalho, 83 pessoas responderam que nunca ocorreu (91,2\%), 8 pessoas responderam que ocorreu de 1 a 3 vezes a necessidade de afastamento $(8,8 \%)$ e nenhuma pessoa respondeu que precisou se afastar por mais de três vezes do trabalho por problemas de saúde relacionados ao trabalho (0\%).

A partir da análise dos dados, observou-se em linhas gerais que a um equilíbrio da população em estudo no fator sexo, pois, apesar da porcentagem maior ser a masculina, a população feminina não está tão a baixo, mostrando que a mulher vem tomando cada vez mais espaço no mercado de trabalho.

Quanto a idade dos servidores, tempo de serviço, número de filhos e estado civil foi observada uma grande quantidade de jovens adultos e adultos a baixo de 41 anos totalizando $91,4 \%$ dos pesquisados, como também $36,3 \%$ da população são solteiros, $67 \%$ não tem filhos e $36,3 \%$ estão a menos de um ano trabalhando na instituição, o que evidencia que as pessoas têm buscado cada vez mais cedo ingressar no mercado de trabalho, como também uma estabilidade financeira, onde, na pesquisa $75,7 \%$ dos pesquisados têm renda acima de três salários mínimos.

Em relação a formação acadêmica dos técnicos administrativos, corroborando com os estudos de Silva (2016), os dados mostram uma formação acadêmica superior ao segundo grau completo o qual é solicitado para ingresso no cargo público, isso ocorre pois melhorias salariais se associam a capacitação profissional, o que é proposto pelo Ministério da Educação(MEC) definidas na Lei $\mathrm{n}^{\circ} 11.091$, de 12 de janeiro de 2005 a qual propõe as Diretrizes para o desenvolvimento do Servidor Público, como também o Plano de Carreira dos Cargos Técnico- 
Administrativos. Quanto ao afastamento do trabalho por problemas de saúde relacionados ao trabalho, grande maioria afirmou nunca ter realizado afastamento por essa causa, porém, isso se deve a um número elevado de pessoas com tempo de serviço a baixo de um ano.

Os resultados apresentados no Alfa de Cronbach foram acima de 0,9 indicando uma classificação muito boa, onde todos os questionários estão atendendo aos critérios dos estudos, ou seja, estão validados, sendo possível utilizar análises estatísticas neles.

\section{Resultados da Escala de Avaliação do Contexto de Trabalho - EACT}

Sabendo que a EACT expressa a organização do trabalho, condições físicas, químicas e/ou biológicas para realização do trabalho, como também a qualidade das relações sócio profissionais, foi analisado cada aspecto citado por meio dos valores das médias.

Tabela 1 - Resultados das respostas dos técnicos administrativos de uma instituição pública em relação ao a organização do trabalho.

\section{ITENS}

\section{MÉDIAS}

O ritmo de trabalho é excessivo 2,9

As tarefas são cumpridas com pressão de prazos

Existe forte cobrança por resultados

As normas para execução das tarefas são rígidas

Existe fiscalização do desempenho

O número de pessoas é insuficiente para se realizar as tarefas

Os resultados esperados estão fora da realidade

Existe divisão entre quem planeja e quem executa

As tarefas são repetitivas

Falta tempo para realizar pausas de descanso no trabalho

As tarefas executadas sofrem descontinuidade

Fonte: Autora (2019).

\section{2,8}


Observando os valores das médias apresentados na Tabela 1, o fator organização do trabalho expressa as representações sobre como ocorre a divisão do trabalho, as normas, o tempo e o controle exigidos para o desempenho de determinada tarefa. Assim, foi observado por meio das médias que o item "as tarefas são repetitivas" teve uma média grave $(3,9)$, apresentando assim uma grande disposição a doenças osteomusculares, pois, quanto mais monótona e repetitiva a atividade, pior as condições osteomusculares.

Assim, para Ferreira e Mendes (2007) quando o resultado é grave há forte risco de adoecimento, necessitando de providencias imediatas das causas, visando eliminá-las e/ou atenuá-las. A maioria dos itens foram classificados como críticos, o que é um alerta principalmente aos chefes dos setores, para rever as formas, ritmo e cobranças no trabalho. O único item considerado como satisfatório foi "os resultados esperados estão fora da realidade" $(1,8)$, isso significa um resultado positivo e produto de prazer no trabalho, que deve ser mantido e consolidado no ambiente organizacional (FERREIRA; MENDES, 2007).

A Tabela 2 representa o segundo fator da escala relacionado à comunicação e a sociabilidade no trabalho, interação profissional com o colega e chefias dos Técnicos administrativos.

Tabela 2 - Resultados das respostas dos técnicos administrativos de uma instituição pública em das relações sócio profissionais.

\section{ITENS}

MÉDIAS

As tarefas não estão claramente definidas

A autonomia é inexistente 2,0

A distribuição das tarefas é injusta

Os funcionários são excluídos das decisões

Existem dificuldades na comunicação entre chefia e subordinados

Existem disputas profissionais no local de trabalho

Falta integração no ambiente de trabalho

A comunicação entre funcionários é insatisfatória

Falta apoio das chefias para o meu desenvolvimento profissional

As informações que preciso para executar minhas tarefas são de difícil acesso

Fonte: Autora (2019). 
Observamos que o item "Os funcionários são excluídos das decisões" foi o único fator crítico apresentado $(2,6)$, o qual muitas vezes deve-se a falta de comunicação dos chefes dos setores para com os técnicos administrativos, ou, simplesmente não ocorre a busca pela opinião dos mesmos, dificultando a comunicação e liberdade no ambiente de trabalho. Porém, todos os outros itens se encontram como satisfatórios na classificação (abaixo de 2,2), o que corrobora com Silva (2013) onde, todos os itens da pesquisa foram classificados como satisfatórios.

Ainda em relação a Tabela 2 os itens com maior grau de satisfação foram "existem disputas profissionais no local de trabalho" e "falta integração no ambiente de trabalho", apresentando uma integração eficaz entre colegas de trabalho (1,9), corroborando com Ferreira e Mendes (2003) que afirma que as estratégias operárias e de mobilização coletiva mantém os trabalhadores mais próximos da saúde. Assim, quanto melhor a relação com os colegas no ambiente de trabalho, menor serão as chances de adoecimento por causas trabalhistas.

$\mathrm{Na}$ Tabela 3 estão representados os fatores de condições do trabalho relacionados ao ambiente físico, equipamentos, material e apoio institucional voltada para o desenvolvimento profissional.

Tabela 3 - Resultados das respostas dos técnicos administrativos de uma instituição pública em relação às condições do trabalho.

\section{ITENS}

\section{MÉDIAS}

\begin{tabular}{lc}
\hline As condições de trabalho são precárias & 2,2 \\
O ambiente físico é desconfortável & 2,4 \\
Existe muito barulho no ambiente de trabalho & 2,3 \\
O mobiliário existente no local de trabalho é inadequado & 2,6 \\
Os instrumentos de trabalho são insuficientes para realizar as & 2,3 \\
tarefas & 2,1 \\
$\begin{array}{l}\text { O posto/estação de trabalho é inadequado para realização das } \\
\text { tarefas }\end{array}$ & 2,3 \\
$\begin{array}{l}\text { Os equipamentos necessários para realização das tarefas são } \\
\text { precários }\end{array}$ & 2,0 \\
$\begin{array}{l}\text { As espaço físico para realizar o trabalho é inadequado de trabalho oferecem riscos à segurança das } \\
\text { pessoas }\end{array}$ & 1,9 \\
O material de consumo é insuficiente & 2,4 \\
\hline Média Total & $\mathbf{2 , 2}$
\end{tabular}

Fonte: Autora (2019). 
Considerando os resultados encontrados na Tabela 3, seis itens foram considerados críticos, onde, o com maior grau de preocupação foi "O mobiliário existente no local de trabalho é inadequado" $(2,6)$, pois, para um trabalho onde na maior parte do tempo o profissional se encontra na posição sentada e em frente a um computador, é imprescindível a utilização de um mobiliário confortável e que se adeque aos padrões exigidos na Norma Regulamentadora 17. A mesma estabelece parâmetros permitindo a adaptação das condições de trabalho às características psicofisiológicas dos trabalhadores, proporcionando o máximo de conforto, segurança e melhor desempenho.

Segundo Ferreira e Mendes (2007) crítico é um resultado mediano, porém, indicador de "situação-limite", o que potencializa o custo negativo e o sofrimento no trabalho. Sinaliza estado de alerta, requerendo providências imediatas a curto e médio prazo.

\section{Resultados da Escala de Custo Humano no Trabalho - ECHT}

$\mathrm{Na}$ Tabela 4 os valores da escala ECHT (Escala de Custo Humano no Trabalho) expressam o que é exigido no contexto de trabalho nas esferas físicas, cognitiva e efetiva do trabalho. Assim como na EACT, considera como resultado para o custo humano no trabalho $(E C H T)$ os seguintes valores: Acima de 3,7 = avaliação mais negativa, grave; Entre 2,3 e 3,69 = avaliação mais moderada, crítico; Abaixo de 2,29 = avaliação mais positiva, satisfatório. 
Tabela 4 - Resultados das respostas dos técnicos administrativos de uma instituição pública em relação ao custo afetivo.

\begin{tabular}{lc}
\hline \multicolumn{1}{c}{ ITENS } & MÉDIAS \\
\hline Ter controle das emoções & 3,0 \\
Ter que lidar com ordens contraditórias & 2,5 \\
Ter custo emocional & 2,7 \\
Ser obrigado a lidar com a agressividade dos outros & 2,6 \\
Disfarçar os sentimentos & 2,6 \\
Ser obrigado a elogiar as pessoas & 1,7 \\
Ser obrigado a ter bom humor & 2,3 \\
Ser obrigado a cuidar da aparência física & 1,9 \\
Ser bonzinho com os outros & 2,1 \\
Transgredir valores éticos & 1,7 \\
Ser submetido a constrangimentos & 1,6 \\
Ser obrigado a sorrir & 1,7 \\
\hline Média Total & $\mathbf{2 , 2}$ \\
\hline
\end{tabular}

Fonte: Autora (2019).

A Tabela 4 que representa o primeiro fator da segunda escala, os itens irão expressar o custo afetivo que é imposto ao trabalhador, o qual será influenciado pelo contexto de trabalho ao qual o trabalhador está inserido, analisando sentimentos, estado de humor e reações afetivas. Assim, na presente avaliação não foram observados pontos graves, porém, seis pontos críticos foram apontados, onde, os dois mais relevantes foram: "Ter controle das emoções" $(3,0)$ e "ter custo emocional" $(2,7)$, o que aponta uma falta de liberdade para expressar o que eles sentem, podendo acarretar em distúrbios emocionais.

A Tabela 5 apresenta o segundo fator que expressa o custo cognitivo ao quais os trabalhadores técnicos administrativos estão expostos no seu contexto de trabalho. 
Tabela 5 - Resultados das respostas dos técnicos administrativos de uma instituição pública em relação ao custo cognitivo.

\begin{tabular}{lc}
\hline \multicolumn{1}{c}{ ITENS } & MÉDIAS \\
\hline Desenvolver macetes & 2,4 \\
Ter que resolver problemas & 3,6 \\
Ser obrigado a lidar com imprevistos & 3,5 \\
Fazer previsão de acontecimentos & 3,0 \\
Usar a visão de forma contínua & 3,7 \\
Usar a memória & 3,8 \\
Ter desafios intelectuais & 3,3 \\
Fazer esforço mental & 3,6 \\
Ter concentração mental & 3,6 \\
\hline Média Total & 3,38 \\
\hline
\end{tabular}

Fonte: Autora ( 2019).

Quando visualizamos os dados da Tabela 5 em relação aos resultados ao custo cognitivo todos os indicadores apresentaram valores preocupantes (acima de 2,4), corroborando com Silva (2013) que afirmou que esse é um dos fatores que mais resultados graves e não possui nenhum resultado satisfatório. Ainda em relação a esses dados dois itens foram considerados graves, que são: "usar a visão de forma contínua" $(3,7)$ e "usar a memória" $(3,8)$. Esse resultado é devido ao trabalho exigir que os técnicos administrativos permaneçam por horas a frente de um computador realizando trabalhos que necessitam do uso contínuo da memória e da visão.

A Tabela 6 expressa o custo corporal que é imposto ao trabalhador técnico administrativo no seu contexto de trabalho, principalmente analisando fatores biomecânicos, fisiológicos, posturais, deslocamentos, gestos e força física. 
Tabela 6 - Resultados das respostas dos técnicos administrativos de uma instituiçãopública em relação ao custo corporal.

\begin{tabular}{lc}
\hline \multicolumn{1}{c}{ ITENS } & MÉDIAS \\
\hline Usar a criatividade & 3,3 \\
Usar a força física & 2,0 \\
Usar os braços de forma contínua & 2,7 \\
Ficar em posição curvada & 2,6 \\
Caminhar & 2,1 \\
Ser obrigado a ficar em pé & 1,7 \\
Ter que manusear objetos pesados & 1,8 \\
Fazer esforço físico & 1,9 \\
Usar as pernas de forma contínua & 1,8 \\
Usar as mãos de forma repetidas & 3,5 \\
\hline Média Total & $\mathbf{2 , 3}$ \\
\hline
\end{tabular}

Fonte: Autora (2019).

Quando observado os dados da Tabela 6 do presente estudo, não foi observado nenhum fator grave, porém, fatores críticos foram encontrados, sendo o item com maior média "Usaras mãos de forma repetidas" (3,5), o que nos leva a um fator relevante para o surgimento de doença ocupacional, as Lesões por Esforço Repetitivo (LER) e Distúrbios Osteomusculares Relacionados ao Trabalho (DORT) que são um conjunto de doenças que atingem, principalmente, os membros superiores e o pescoço. Várias situações de trabalho favorecem odesencadeamento de LER/DORT, dentre elas, o trabalho repetitivo que afeta significativamente pessoas que trabalham com computadores e digitam por horas todos os dias.

\section{CONCLUSÃO}

Os resultados encontrados demonstram que no trabalho dos técnicos administrativos da Universidade Estadual da Paraíba (UEPB) existem vivências de prazer, mas, também de sofrimento, onde, o prazer está relacionado as relações sócio profissionais e nos fatores sociais e psicológicos. Já o sofrimento surge na 
organização do trabalho, cognição e custo físico devido à falta de pausas, muito tempo sem alternar a postura e dor em toda a coluna e membros superiores. Assim, a partir dessa pesquisa percebe-se a importância de um olhar voltado para a saúde do trabalhador, onde, os riscos de adoecimento são visíveis, o que gera uma responsabilidade para o melhor cuidado da saúde dos técnicos administrativos da referidauniversidade.

Para que haja uma melhora na saúde desses trabalhadores é necessário investir em atenção e promoção da saúde, com palestras e informes sobre o que pode ser mudado para queos pontos negativos apresentados na pesquisa se tornem pontos de prazer. É necessário que o trabalhador conheça a Política Nacional de Saúde do Trabalhador e da Trabalhadora (PNSTT), as quais definiram os princípios, as diretrizes e as estratégias a serem observados pelas três esferas de gestão do Sistema Único de Saúde (SUS), para o desenvolvimento das ações de promoção, vigilância, diagnóstico, tratamento, recuperação e reabilitação da saúde do trabalhador.

Também é necessário que seja realizada uma Análise Ergonômica do Trabalho proposta pela Norma Regulamentadora 17 a qual irá avaliar a adaptação das condições de trabalho às características psico fisiológicas dos trabalhadores, alterando assim todo o mobiliário que estiver fora dos padrões descritos na norma. Portanto, a partir dessa pesquisa percebe-se a importância de dar continuidade a esse tipo de trabalho, pois, os riscos de adoecimento nos técnicos administrativos são visíveis. Outras pesquisas na área podem dar continuidade ao cuidado com a saúde do trabalhador, com avaliações mais minuciosas e com uma maior população, para ser realizada uma análise ainda mais detalhada. 


\section{REFERÊNCIAS BIBLIOGRÁFICAS}

BRASIL. Ministério da Saúde. Saúde do Trabalhador. Caderno de atenção básica $n^{\circ} 5$. Brasília, 2018.

CAMPOS, N.M. Qualidade de vida no trabalho dos servidores técnico-administrativos do Instituto Federal Sul-rio-grandense lotados em Pelotas. 2016. Dissertação (Mestrado) Programa de Pós-Graduação em Política Social, Universidade Católica de Pelotas, Mestrado em Política Social, Pelotas, 2016.

COSTA, Marina Carvalho Vieira da Costa. Qualidade de vida no trabalho de funcionários técnico-administrativos terceirizados e não terceirizados de uma universidade pública. 2017. 138 f. Dissertação (Mestrado em Educação, Ambiente e Sociedade) - Centro Universitário das Faculdades Associadas de Ensino - FAE, 2017.

FERREIRA, M. C.; MENDES, A. M. Trabalho e riscos de adoecimento: o caso dos auditores fiscais da Previdência Social Brasileira. Brasília: Edições LPA e FENAFISP, p. 67-79 2003.

FERREIRA, M. C.; MENDES, A. M. Inventário sobre trabalho e riscos de adoecimento ITRA: instrumento auxiliar de diagnóstico de indicadores críticos no trabalho. In: MENDES, A. M. (Org.). Psicodinâmica do trabalho: Teoria, método e pesquisas. São Paulo: Casa do Psicólogo, 2007.

ORGANIZAÇÃO INTERNACIONAL DO TRABALHO. La prevención de las enfermedades profesionales. Organização Internacional do Trabalho, 2013. 19 p.

OLIVEIRA, S. G. Abrangência do conceito acidente de trabalho. Indenizações por acidentes de trabalho ou doença ocupacional. 7. ed. São Paulo: LTR, 2013. p. $42-61$.

RIBEIRO, M. C. S. Enfermagem e Trabalho: fundamentos para a atenção à saúde dos trabalhadores. 2. Ed. São Paulo: Martinari, 2012.

RIBEIRO, V.; SANTOS, C.; MANCEBO, D. O servidor público no mundo do trabalho do século XXI. Psicologia: Ciência e Profissão, Brasília (DF), v. 33, n. 1, 2013.

SILVA, Ana Cláudia Colaço Lira. Fatores de Risco e Prevalência de Queixas Musculoesqueléticas entre Técnicos-administrativos em Educação: estudo realizado na Universidade Federal de Pernambuco. 2016. 169 f. Dissertação (Mestrado em Ergonomia) Universidade Federal de Pernambuco, 2016.

SILVA, Ana Cláudia Colaço Lira. Fatores de Risco e Prevalência de Queixas Musculoesqueléticas entre Técnicos-administrativos em Educação: estudo realizado na Universidade Federal de Pernambuco. 2016. 169 f. Dissertação (Mestrado em Ergonomia) Universidade Federal de Pernambuco, 2016.

TRAESEL, E. S.; MERLO, A. R. C. "Somos sobreviventes": vivências de servidores públicos de uma instituição de seguridade social diante dos novos modos de gestão e a precarização do trabalho na reforma gerencial do serviço público. Cadernos de PsicologiaSocial do Trabalho, v. 17, n. 2, pp. 224 238, 2014. 